\title{
Critical Condition of Sewage Network
}

\begin{abstract}
The paper presents the methodology formulated for determining the critical technical state of operating sewer pipes that is based on statistical-stochastic modeling. It describes the theoretical boundary between the area comprised of pipes that do not show any damage or require only maintenance measures and the area comprised of pipes that require renovation.

The study includes concrete collectors with dimensions of DN 600/1100, $800 / 1200$, and $900 / 1350 \mathrm{~mm}$, stoneware pipes of with diameters ranging from DN $200 \mathrm{~mm}$ to $400 \mathrm{~mm}$, and stoneware connections (DN 100-200 mm). The statistical modeling phase was carried out using Weibull distribution, and its parameters were evaluated by the method of moments. In contrast, the stochastic studies were based on a combination of the method of moments and Monte-Carlo mathematical simulations. On the basis of the proposed forecasting, it was possible to carry out a qualitative and quantitative analysis of the technical condition of the exploited sewage systems. Quantitative analysis helped us to determine the necessary range of renovation, which is an important operation component of every linear sewage network.
\end{abstract}

Keywords: sewage network, critical state of sewerage network, Weibull distribution, Monte-Carlo simulation

\footnotetext{
* Zweckverband zur Abwasserbeseitigung im Hachinger Tal Rotwandweg, Taufkirchen, Germany
} 


\section{Introduction}

Forecasting the technical condition of a sewage system is aimed at optimizing its management. European cities spend several billion euros in a one-year period for renewal of their water supplies and sewage systems. In the next decades, a further increase in these costs should be take into account due to the steadily progressive destruction of urban infrastructure. Forecasting the technical condition of sewage systems in order to optimize the scope of renovation (which is the most-important component of their exploitation) is an effective way of stopping these destructive processes and to reasonable finance the rehabilitation procedures.

\section{Purpose and Scope of Work}

The main aim of this work is to formulate a methodology for forecasting the technical condition of municipal network, taking into account the different boundary conditions of its operation. On the basis of the elaborated forecast methodology, the actual state of a linear object is determined that allows for its rational exploitation by an efficient planning of the scope of maintenance and renovation. An economical exploitation of a sewage system is important in the era of diminishing water intake, causing a reduction in the discharge to sewage systems. The result of these trends is the shrinkage of the financial resources available to the exploiters of the network. An important and expensive component of sewage system exploitation is its renovation.

The quality and range of the implemented renovation are essential to ensure the full availability of the sewage facility during the period of the established technical viability defined by its tightness, capacity, and functionality.

The application of the Weibull model in combination with the Monte-Carlo method allows us to determine the critical technical and operational state of sewage linear objects on the basis of empirical data and make a conclusion about the actual technical condition of the object. This approach provides the possibility of having a detailed insight into many aspects of network exploitation, which is of strategic cognitive importance as well as high application values, and it meets the expectations of linear sewage object managers.

An innovative combination of the Weibull distribution with the Monte-Carlo method provides an original and more-accurate description of the available empirical material in conducting an analysis of the technical and operational state of the linear objects of urban infrastructure and represents a significant advance in the studies whose purpose is the practice of exploitation. The application of the Monte-Carlo method affects a significant expansion of the database and allows us to give essential credibility to the correctness and relevance of the research in a theoretical aspect.

The proposed methodology simplifies the entire procedure of forecasting and analyzing the technical and operational state of linear objects of an urban infrastruc- 
ture. It turns out that, even with a small database, it allows us to obtain a reliable assessment of the actual state of the object, taking into account the different conditions of its operation. The application of the developed methodology allows to optimize the exploitation of different systems of urban infrastructure relying on the pursuit to maximize the duration of their full accessibility by using the minimum financial outlay.

The scope of this work covers the issues related to the statistical and stochastic modeling of the critical technical and operational state of a sewage system under conditions of its functioning in the catchment area of the Hachinger Bach stream. The database of the completed research documentation is a full-range optical inspection. The critical technical and operational condition is defined as the boundary between the area of network accessibility reserved within a range engaging the maintenance procedures and the area foreseen for the use of the rehabilitation techniques and technologies. This boundary sets a very important point on the exploitation time scale of linear sewage systems, since it begins an accelerated growth of damage which can lead to irreversible consequences and sometimes even construction disaster.

During the statistical studies for the theoretical interpretation of the empirical data, a two-parameter Weibull distribution and perpendicular method of moments were used. During this phase, the heterogeneous conditions of network operation were taken into account: the material from which the pipes were made, their role in the linear object, the influence of the depth of the pipe foundation, and the ground water.

The phase of the stochastic modeling of the critical technical and operational state was done using a similar scheme as in statistical modeling, wherein the Monte-Carlo method was used to estimate the Weibull parameter. Mathematical simulations allowed to stochastically increase the number of random samples and the accuracy of the test results. In the discussion, an analysis of the age structure of the pipes were used along with the technical and technological network characteristics.

\section{General Characteristics of the Research Object}

The object of the research is the sewage system exploited by the Target Association called Zweckverband zur Abwasserbeseitigung im Hachinger Tal. It discharges municipal sewage from three municipalities in Bavaria - Oberhaching, Unterhaching, and Taufkirchen - located in the Hachinger Bach stream catchment in the southeast part of Munich. The construction of sewage infrastructure began in the mid-50s of the last century (Fig. 1). Until 2000, when the first full-range optical inspection was made, this network had been built according to the standards developed by the city of Munich (entitled Münchner Normalien [10]). $76.61 \%$ of the network's total length is formed by pipes made of German stoneware (Fig. 2). The share of concrete pipes is only $13.30 \%$, and occasionally, the represented materials are polyethylene HD-PE (3.21\%) and nodular cast iron (3.21\%). 


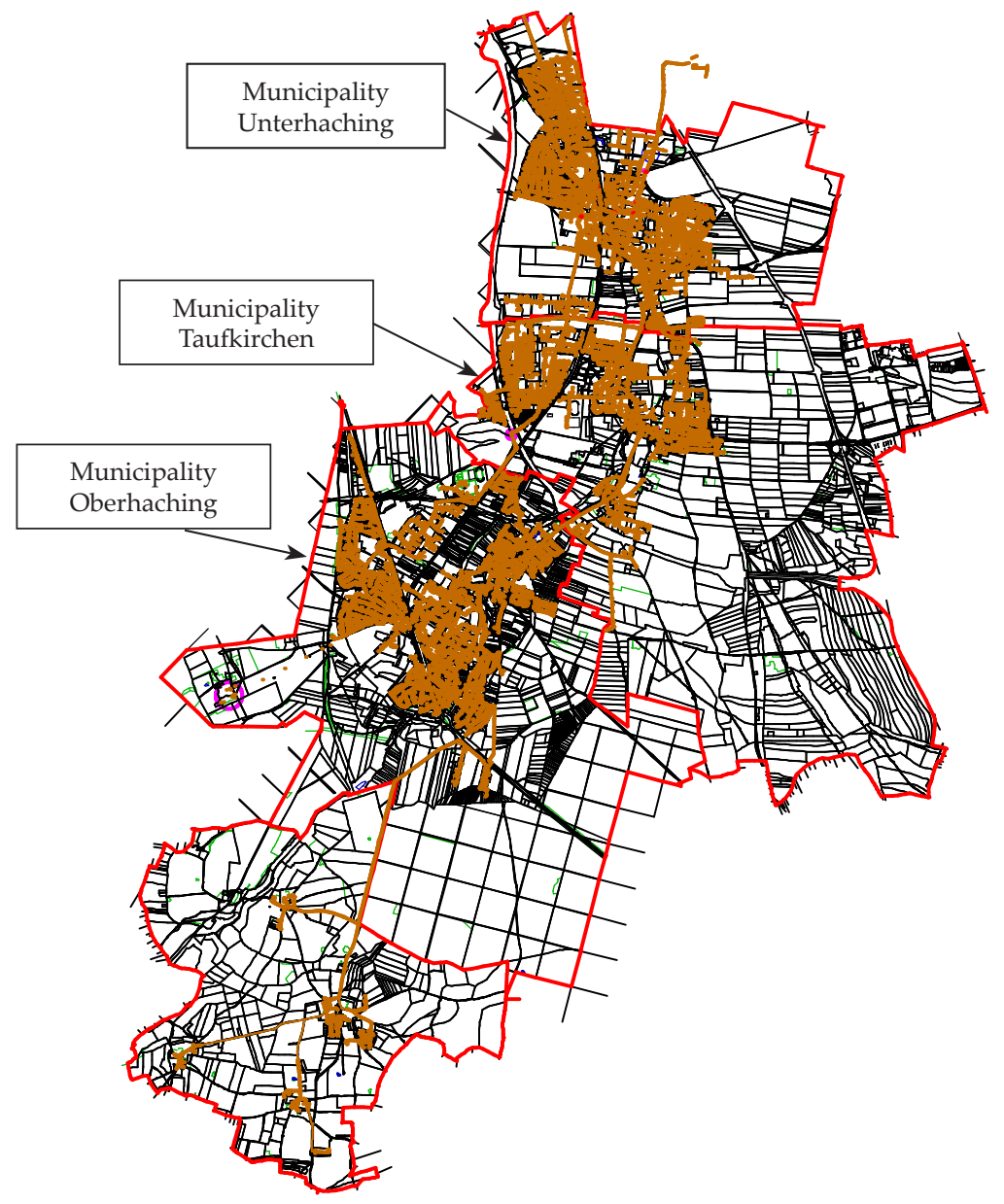

Fig. 1. Sewage infrastructure in Hachinger Bach stream catchment area

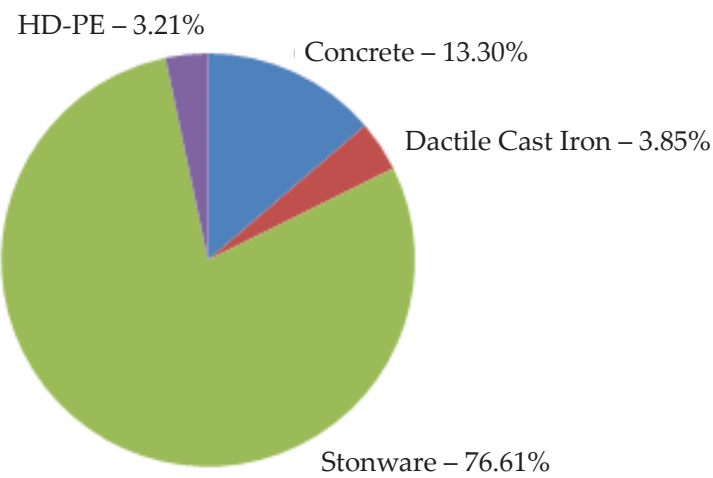

Fig. 2. Material composition of network in Hachinger Bach stream catchment area 


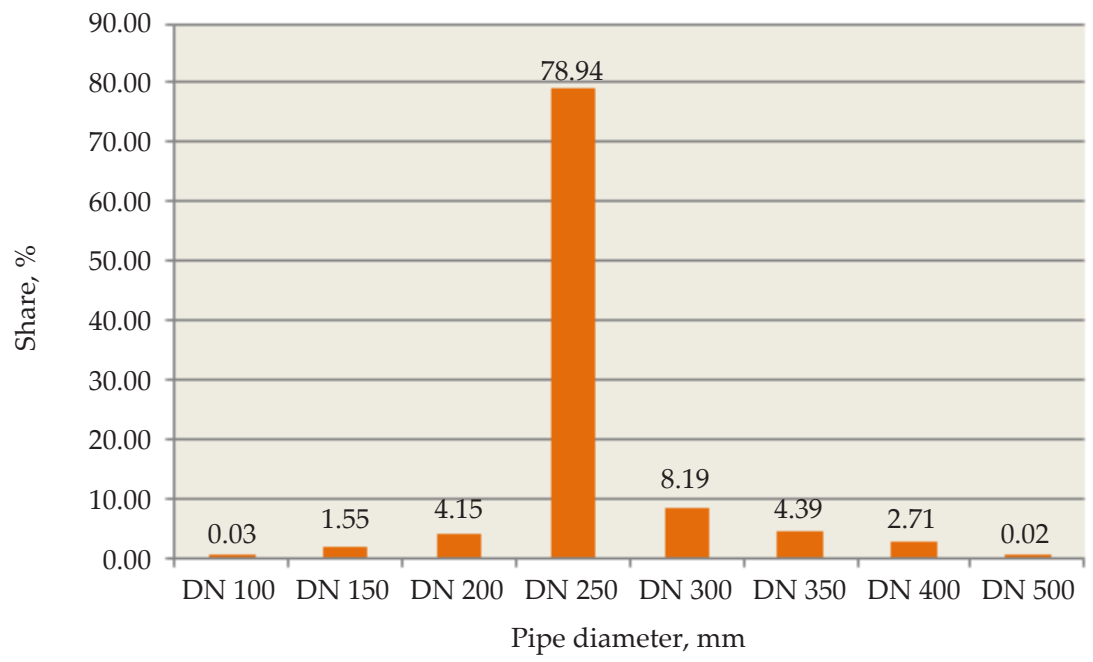

Fig. 3. Structure of stoneware sewer pipes diameters

The structure of the stoneware pipe diameters is shown in Figure 3. It follows from this that the dominant inner diameters are DN $250 \mathrm{~mm}$. Münchner Normalien envisaged the construction of sewer pipes of diameters up to DN $500 \mathrm{~mm}$ made only from German stoneware backfilled by break stone with a grain size of $4-8 \mathrm{~mm}$ (called Riesel). The choice of this type of backfill was dictated by ground conditions occurring in the catchment area of the Hachinger Bach stream characterized by coarse gravel partly interleaved with silts and clays.

In addition to the stoneware pipes, the network also includes three concrete collectors. Two of them (the eastern and western collectors) run parallel to each other from the southern to the northern part of the Hachinger Bach stream catchment. The third collector is a perpendicular connection to the eastern collector that discharges sewage from the eastern-most area of the Unterhaching municipality. The collectors are made of B10 concrete elements molded in "wet technology." The pipe with an elevated egg-profile has a diameter of DN 600/1100 mm and of normal profile - DN 800/1200 and 900/1350 mm.

The sewage infrastructure in the Hachinger Bach stream catchment area discharges municipal sewage that meet the values of the physicochemical parameters defined in the German guidelines for municipal wastewater. Therefore, they can be introduced into the network without pre-treatment [14]. Because Hachinger Bach is a small watercourse in hydrological terms, it was necessary to connect the entire sewage infrastructure to the Munich city network. A series of gravel tracks occurring in the subsoil enables rainwater infiltration through the wells. A favorable morphology of the Hachinger Bach stream catchment allows for gravitational sewage transport, and the average longitudinal sewer pipes decline are $3-5 \%$.

The depth of the sewer pipe foundation is from $2 \mathrm{~m}$ to $4 \mathrm{~m}$ below ground level. Due to the locally occurring depressions, it was necessary to build ten pump stations 
with pressurized transport pipes. Seven stations work in the pneumatic system. This data indicates a high homogeneity of the studied sewage network due to the material of its pipes, their diameter, and the depth of the foundation.

The Target Association exploits the sewage system based on the database from the Magellan operating system [5]. It provides a direct connection between the database and graphics. During the years of 2000-2003, the Bavarian Office for Surveying managed to measure the entire territory of Bavaria and develop a numerical map of the area (Digitale Flurkarte). Thanks to the continuous development of the Magellan database (which has operated online for more than a year), it was possible to download the various thematic maps over the internet, such as the ground water isohypses map, geological and green space maps, etc. These maps are essential when planning the development of a sewage network.

After the first full-range network optical inspection, all of the results of the research were introduced to the database. Similarly, this was done for the documentation of the renewal of municipal networks. For 15 years, the database has been an important instrument of exploitation, which is also important when planning a renovation of the network.

The Hachinger Bach stream catchment is located in the area of a geological formation known as the Munich Gravel Platform (Münchner Schotterebene). It is built from coarse gravel partly interleaved by silts and clays. Its outline is triangular in shape, with an area of approximately $1500 \mathrm{~km}^{2}$. Münchner Schotterebene is inclined in the direction from southwest to northeast, and the difference in height is about $300 \mathrm{~m}$. The maximum thickness of the tracks of gravel reaches $100 \mathrm{~m}$. Münchner Schotterebene aroused as a result of three successive glaciations (the Mindeleiszeit, Rißeiszeit, and Würmeiszeit), which had a decisive influence on its geological structure [7].

The main direction of the groundwater flow takes place from south to north and is consistent with the direction of the inclination of the whole platform. The water table within the Munich Gravel Platform occurs at a depth of 1-13 m from ground level. Thirty percent of the network operates in the zone of groundwater table fluctuations. This problem occurs in the municipality of Oberhaching and Taufkirchen. In the municipality Unterhaching, the sewer pipes are sited approximately $3 \mathrm{~m}$ from ground level, and the groundwater occurs at a depth of $7 \mathrm{~m}$.

Concrete collectors are the main sewage transport line. The pipe length of the elevated egg-profile (DN 600/1100 $\mathrm{mm}$ ) is 10,886 $\mathrm{m}$, and the pipes of a normal egg-profile (DN DN 800/1200 and 900/1350 mm) - 10,529 m. In total, they represent $13 \%$ of the length of the entire network without taking into account the connections. In accordance with the principles contained in the Münchner Normalien [10], the concrete canals were built from unarmed concrete B10 molded in the "wet" technology. In the previously prepared pit, the bottom portion of the canal was first concreted as a single section with a length of $1.0 \mathrm{~m}$ to $1.5 \mathrm{~m}$, and then the vault was made (Fig. 4). As a result of such adopted technologies, two longitudinal stitches were created, working on the entire length of the canal and the radial end of each section. After 
cleaning, the working stitches were scuffed by cement-sand mortar [11], and clinker tiles were laid at the bottom of the canal. Inspection chambers were made of concrete B10 (also poured the "wet" way) and was connected combined articulately with the pipes. The Munich principle of building canals did not assume any dilatation for this rigid structure, which seriously hindered its subsequent operation. The functioning of each sewer line in the subsoil is associated with the impact of the definite resultant tension on it. It has a negative impact on the most-vulnerable elements of the construction - the working stitches.

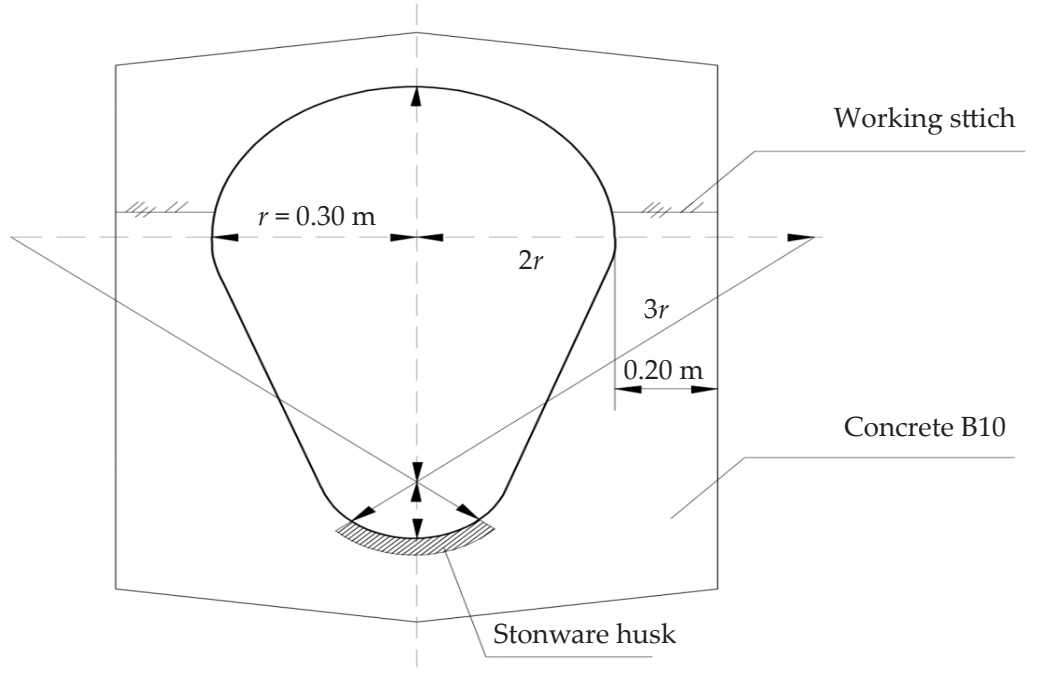

Fig. 4. Cross-section of concrete canal DN 600/1100 mm

Source: [12]

The above design and construction drawbacks hinder the operation of the concrete collectors operating in the zones of fluctuations of the ground water level [12]. The infiltration of ground water into the interior of the canals takes place there. Water infiltration is important when the exploited network does not have its own sewage treatment plant. The main objective of a network exploiter is to reduce water infiltration by sealing the damaged parts of the network.

The length of the concrete collectors operating in the zone of fluctuations of the ground water level is $6184 \mathrm{~m}$, which represents almost $30 \%$ of their total length and $4 \%$ of the entire sewage infrastructure. With the systematic monitoring of this part of the network, it is possible to register all leaks in the network. Operations conducted earlier focused only on sealing the concrete collector with a polyurethane resin or a mixture of minerals. This type of work must be implemented comprehensively, because sealing a single point of the network causes a local rise in the ground water and infiltration in previously hermetic sections. 
The total length of the stoneware sewer pipes in the catchment area of the Hachinger Bach stream is $124,755 \mathrm{~m}$, which represents $80 \%$ of the total length of the network. The dominant diameter of the stoneware pipes is DN $250 \mathrm{~mm}$ (Fig. 3). Until 1965, the production of stoneware pipes in Germany did not provide the factory incorporation of sealing for their connections. Impregnated tow in the bituminous substrates or cannabis cord were a commonly used type of sealing at that time. The turn occurred in 1965, when the incorporation of elastomer (EPDM) and polyurethane (PU) sealing elements permanently began. For stoneware pipes laid in opened trenches, three basic types of connections are used: system F, C, and S [13].

Stoneware pipes that are traditional materials in sewage systems are among the so-called group of rigid pipes that have very good strength properties. The advantages of stoneware are its durability, resistance to corrosion and leaks, low roughness, abrasion resistance, and trouble-free recycling. Regardless of the effective sealing of the joints, modern stoneware pipes also have thickened wall to increase their resistance to being smashed and improper laying and backfilling in the trench. An additional advantage of stoneware compared to other materials is its easy renovation. Like every materi$\mathrm{al}$, however, stoneware also has disadvantages. A significant drawback of stoneware is its fragility, requiring the careful handling of pipes until their backfilling in the trench.

An important component of the studied sewage infrastructure are the connections (laterals). Their number as of January 2013 was 8383, and their total length is $95,200 \mathrm{~m}$. These objects connect the public canal with the revision chamber located within the property. For this reason, exploitation of the laterals is partly public and partly private. Their technical and operational condition is much worse than the state of the public canals. It is assumed that the number of defects per $1000 \mathrm{~m}$ of laterals is twice the number of defects per $1000 \mathrm{~m}$ of public canals.

The connections in the catchment area of the Hachinger Tal stream are 99\% made of German stoneware in the range of DN 100-200 mm. The Target Association is responsible for the construction and exploitation of the connections up to the property boundary.

\section{Statistical-Stochastic Modeling of Critical State of Sewage Network}

Forecasting the technical and operational state of the network discharging municipal sewage from the Hachinger Bach stream catchment is based on the dependence of the technical state of the pipes and their age. The basis of the classification of the damages and technical state were two full-range optical inspections carried out in 2000 and 2010. Both classifications of public canals were carried out according to the ATV-M 149 guidelines [1], and the connections according to DIN 1986-30 [3]. Following the exploitation practice, it was assumed that the oldest sections of the network were in the worst condition. In order to simplify the forecast of the technical condition of the object, the concept of critical state was introduced to the exploitation terminology. It boils down to 
a complex forecast to a significant moment in which the transition of the network sections occurred from the state of requiring maintenance to that of requiring renovation.

The use of technical condition assessment based on the analysis of the damages was possible, because the examined network has the desired characteristics. It operates as a separate system, which eliminates the hydraulic problems. The production of the local industrial plants does not adversely affect the physicochemical properties of the sewage. The location of the network does not interfere with the zones of groundwater protection.

Modeling the technical and exploitation state of this network was carried out in a statistical and stochastic phase. Statistical studies were based on a two-parameter Weibull model widely used to predict the reliability of various types of equipment and buildings. This distribution was first applied in 1939 by Swedish researcher Waloddi Weibull in the theory of material fatigue [15]. The first parameter of the Weibull distribution is characteristic service life $T$ specifying the scale of the curve along the $x$-axis. Characteristic service life can be treated as the average value of the Weibull distribution; therefore, the growth of this parameter brings the failure curve offset to a longer service life. The second distribution parameter $b$ is the measurement of the steepness and asymmetry of the distribution. Depending on the value of parameter $b$, it can be described the three specific fragments of failure density graph having the form of the tub.

The Weibull model has the following mathematical conditions [16]:

- density function:

$$
\begin{aligned}
& f(t)=\mathrm{d} F / \mathrm{d} t \\
& f(t)=b / T \cdot(t / T)^{b-1} \exp (-t / T)^{b}
\end{aligned}
$$

- failure function:

$$
F(t)=1-\exp (-t / T)^{b}
$$

- reliability function:

$$
R(t)=\exp (-t / T)^{b}
$$

- failure density:

$$
\begin{aligned}
& \lambda(t)=f(t) / R(t) \\
& \lambda(t)=b / T(t / T)^{b-1}
\end{aligned}
$$

where:

$t$ - statistic variable (for example, service life of the object in years),

$T$ - characteristic service life of distribution corresponding to the mean value of distribution (in years),

$b$ - parameter of distribution form. 
Weibull distribution parameters $b$ and $T$ can be estimated using graphical and analytical methods and obtain a high conformity of the theoretical function with empirical data. Applying the above methodology for the analysis of technical and operational network conditions, the theoretical curve of the reliability $R(t)$ probability can be determined for each renovation class. The concept of failure should not be understood literally but as a phase of the transition of the pipe section from one to the next lower class of the technical condition in a very short period of time.

One of the analytical methods that allows to estimate the parameters $(b, T)$ in a short calculation time is the perpendicular method of moments. The choice of the method of moments is not accidental, because the purpose of further studies is the intended research task consisting of the estimation of the Weibull distribution parameters by the time-consuming method of the Monte-Carlo mathematical simulation.

In the initial phase of the research, a classification of the defects and technical conditions of the sewer pipes was carried out, which creates a database. As part of any further classifications for each type of pipe and boundary condition of network operation, random samples were created consisting of sections classified to the fifth, fourth, and third classes of renovation. These data sets made it possible to draw a line between the area of maintenance and renovation.

On the basis of the prepared database, the preliminary surveying and statistical-stochastic modeling of the critical state for each type of sewer pipe were made in the context of the foundation depth and groundwater level. The critical technical-operation condition is described by the transition function from the maintenance state to the renovation state. The choice of the critical transition function significantly simplified the analysis of the operation of this municipal network under different boundary conditions.

In the stochastic phase of the research, an original combination of the Weibull distribution was employed with mathematical simulations using the method of Monte-Carlo (MMC). The use of the above methodology allowed us to obtain greater accuracy in the model test results. The concept of the Monte- Carlo method does not refer to only one algorithm but to a certain group of numerical methods that use random numbers for approximation solutions or the simulation of different processes.

In order to estimate the Weibull parameters, the inversion method was applied, enabling the realization of any number of mathematical simulation for the age of pipes $t_{1}, \ldots, t_{n}$ in accordance with adopted distribution function $F$. If $F: R \rightarrow[0,1]$ is a definite distribution function, its inverse function is $F^{-1}$, and $Y \approx U(0,1)$ is a random variable with uniform distribution, it can be assumed that $X:=F^{-1}(Y)$. Therefore, it can be assumed that $X \approx F$. This, in turn, means that the distribution function of random variable $X$ is adopted as outset actual distribution function $F[9]$. 
In the case of the Weibull distribution and its inverse function, the age of the analyzed sewer lines is determined according to following formula:

$$
t_{i}^{k^{*}}=\hat{T}\left(\ln \left(\frac{1}{1-U_{i}^{k^{*}}}\right)\right)^{\frac{1}{b}}
$$

where:

$t_{i}^{k^{*}}-$ simulated age of sewer pipes (in years),

$\hat{T}$ - characteristic service life of sewer lines determined by any analytical method (in years),

$b$ - parameter of distribution form determined according to any analytical method,

$U_{i}^{k^{*}}-$ random variable with uniform distribution $\left(0<U_{i}^{k^{*}}<1\right), k^{*}=1,2, \ldots, N$.

In order to obtain a sufficiently large number of random variables with a uniform distribution, one of the most-popular generators was used - the Multiplicative Linear Congruential Generator [8]. Its formula has the following form:

$$
x_{i+1}=\left(a x_{i}+c\right) \bmod m
$$

where:

$$
\begin{aligned}
x_{i} & =\text { random variable; } \\
a & =6909 ; \\
c & =23,606,797 ; \\
m & =2^{32} .
\end{aligned}
$$

The length of the repeated numerical sequences in this case is $m$. As a result of the performance of multiple trials, the appropriate algorithms were determined to find the values of $x$ for 1000, 2500, 5000, 10,000, and 15,000 mathematical simulations:

$$
\begin{aligned}
& \operatorname{MMC}(1000): x_{1}=3000, x_{2}=3000+58, \ldots, x_{1000}=3000+999 \cdot 58 \\
& \operatorname{MMC}(2500): x_{1}=1500, x_{2}=1500+22, \ldots, x_{2500}=1500+2499 \cdot 22 \\
& \operatorname{MMC}(5000): x_{1}=1500, x_{2}=1500+12, \ldots, x_{2500}=1500+4999 \cdot 12 \\
& \operatorname{MMC}(10,000): x_{1}=500, x_{2}=500+6, \ldots, x_{10000}=500+9999 \cdot 6 \\
& \operatorname{MMC}(15,000): x_{1}=500, x_{2}=500+3, \ldots, x_{15000}=500+14999 \cdot 3
\end{aligned}
$$

The phase of the stochastic modeling was based on the method of inversion belonging to the Monte-Carlo family of methods. For this purpose, inverse function $F^{-1}$ was created from Weibull function $F$; on this basis, the age of pipe $t$ was determined, which then was mathematically simulated in accordance with Equation (7). 
In the place of the $F$ distribution, random variables with a uniform distribution of adopting range $(0,1)$ were inserted. The performance of the mathematical simulation allowed for the stochastic enlargement of the number of random samples to be tested. The data obtained from the simulation was reintroduced to the perpendicular method of moments (MM) for a more-accurate estimation of the Weibull parameters. Output values of parameters $b$ and $T$ were taken from previously conducted statistical studies. Random variables with a uniform distribution were generated on the basis of the Multiplicative Linear Congruential Generator (8).

In the last phase of the study, the modeling results of the critical condition of the sewer pipes were compared, taking into account their operating material, type, foundation depth, and the presence of ground water. Within these comparisons, the impact of the operating material and types of canals was determined on the technical condition of sewer pipes located at different depths and above and below the groundwater table. The analysis takes into account the important aspects of the execution technology of different types of sewer pipes and their age structures.

A detailed analysis of the critical state of the sewage infrastructure in the Hachinger Bach stream catchment area helped to determine the actual condition and accurate assessment of the exploited linear object. It was also possible to make a detailed insight into the problems of the network's building state, taking into account the different conditions of its operation. Another important result of the performed studies was the opportunity to thoroughly determine the extent of the renovation, constituting the basis for designing a renovation strategy and balancing the necessary financial resources.

The results of the statistical and stochastic research carried out should be considered as meaningful, since the number of random samples representing all types of pipes was great and the boundary conditions of the network showed a homogeneous nature. The number of the smallest random sample was 100 elements, which in statistical terms creates a solid foundation for research. The homogeneity of the operation conditions of the examined network provided by homogeneous ground conditions occurring across the Hachinger Bach stream catchement. The second factor is the uniform load of traffic on the municipal roads within which the sewer lines run. So, the features differentiating the exploitation of the network are the operating materials, type of pipes, foundation depth, and presence of ground water.

The original aspect of the study was a consideration of the stoneware connections, which are an integral part of each part of the linear sewage infrastructure. In the recent past, the connections were not debated regarding the technical condition of sewage networks and their renovation. One reason for this situation was the lack of technical means that enabled the optical inspection and renovation of sewer pipes with a DN of $\leq 150 \mathrm{~mm}$ [6]. In the last decade, the connections have become a central topic of scientific discussions on the renovation of sewer pipes. An additional impulse to take concrete action towards the connections was the publication of DIN 1986-30 in 2003 [2] and its amendment in 2012 [3] as well as the development of special DIN SPEC 19748 [4] containing the guidelines for renovation. 
In DIN 1986-30 from 2003 [2], the unusual notation appeared, obligating all property owners to control of exploited connections by the end of 2015. This notation turned out to be an effective instrument for stimulating the technical progress in the field of research and the recovery of connections. Connections exploited exclusively by property owners are not in the spotlight of public infrastructure exploiters. Property owners are not aware of their responsibilities and are not willing to finance the maintenance and renovations treatments.

Another legislative variant assumes that the connections run partially in private areas and partly in public areas. With this configuration, the operator of the public network is responsible for the technical condition of the connections up to the border of the property. The Target Association exploits the network connections up to the border of the property and realizes the renovation of the connections up to the inspection chamber with the implementation of its completion.

\section{Results of the Performed Modeling}

Comprehensive research and an analysis based on rich empirical material allowed us to draw an important conclusion of cognitive and application importance, which the best verifier will be by the practice of exploitation:

1. The two-parameter Weibull distribution, in combination with the perpendicular method of moments, is the practical tool that enables the effective statistical modeling of the critical technical-operation condition, describing the transition from the state of maintenance to the state of renovation of various types of linear urban infrastructure.

2. The application of 10,000 mathematical simulations based on the Monte-Carlo method turned out to be a successful way of determining the boundary between the areas of maintenance and technical renovation of the linear objects.

3. The stochastic modeling of the critical technical and operation state of the sewer pipes functioning above the groundwater table showed that the concrete collectors are in the best condition; in slightly worse condition are the stoneware sewer lines, and the worst state is presented by the connections (Fig. 5).

4. On the basis of the research, it was clearly established that the presence of ground water has a negative effect on the exploitation, operation, and technical state of sewer pipes and connections (Fig. 6).

5. The stochastic modeling studies made it possible to demonstrate the positive impact of a deeper foundation for all types of sewer pipes as pertains to their technical and operational states.

6. In each of the three levels of foundation $(G<2 \mathrm{~m}, 2 \leq G<4 \mathrm{~m}$, and $G \geq 4 \mathrm{~m})$, a visible tendency showed that the technical condition of the stoneware sewer pipes was better than the technical condition of the connections. 
7. An analysis of failure showed that the ratio of the frequency of connection damage to the frequency of public canal damage is 137.50:66.34. Then, the ratio value of 2.07:1 determined in the studies is consistent with the generally adopted ratio of 2:1.

8. The technical-operational state of the stoneware connections functioning completely or partially below the ground water table (GWL) should focus special attention on sewage networks exploiters, because they are a significant source of ground water infiltration into sewer pipes (Fig. 7).

9. The model research allows us to perform an analysis of the technical condition of the exploited network in qualitative and quantitative terms.

10. From the quantitative analysis, the necessary scope of the examined network renovation was defined at $40 \%$. Therefore, the fixed scale of renovation needs in the Hachinger Bach catchment area is greater than the general rate of $30 \%$ in Germany.

11. Taking into account the pipe-foundation depth in the analysis of the technical condition, it was shown that, in the initial period of operation lasting up to 25 years, the shallowly placed main sewer lines have the best technical condition, and the deepest ones - the worst. Only in the next phase of network operation (after 25 years) does the network technical condition have a standard well-known character; this means that the deeply located sewer lines are definitely in the best condition, and the shallowly located - the worst.

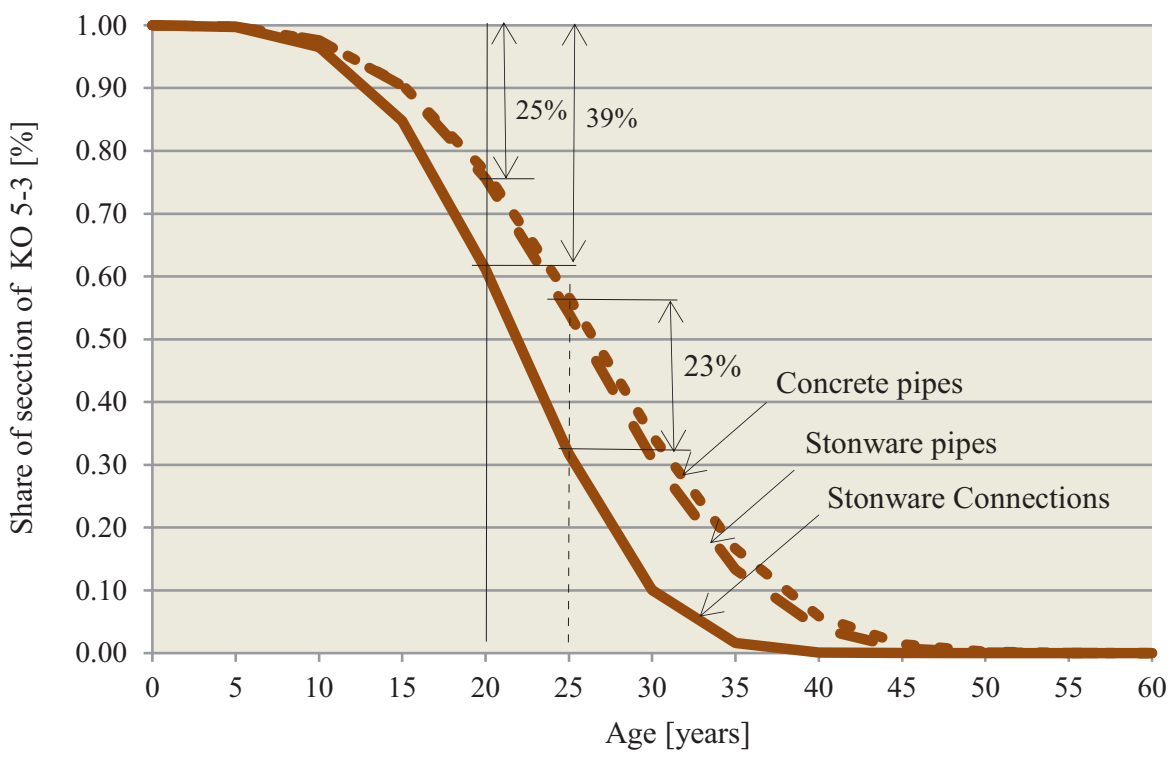

Fig. 5. Course of critical Weibull functions according to MMC for concrete pipes, stoneware sewer pipes, and stoneware connections operating above GWL 


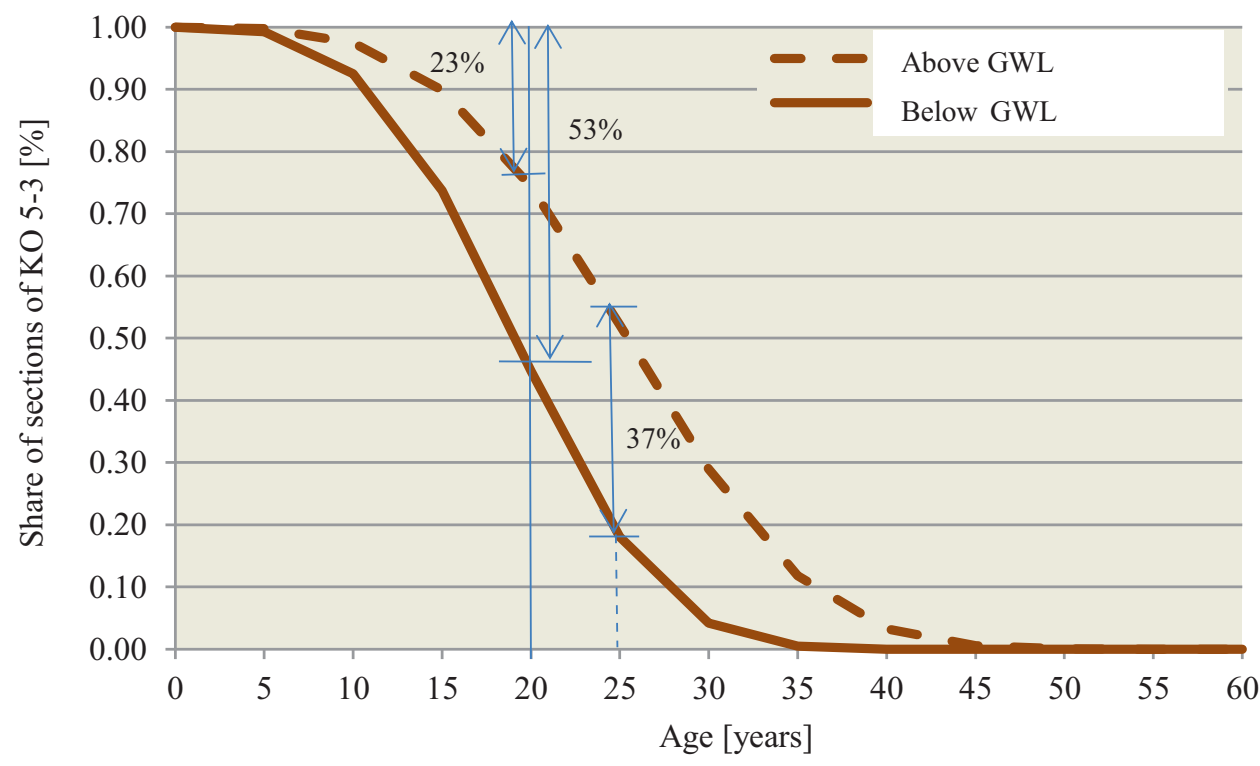

Fig. 6. Course of critical Weibull functions according to MMC for stoneware sewer pipes depending on their position in relation to GWL

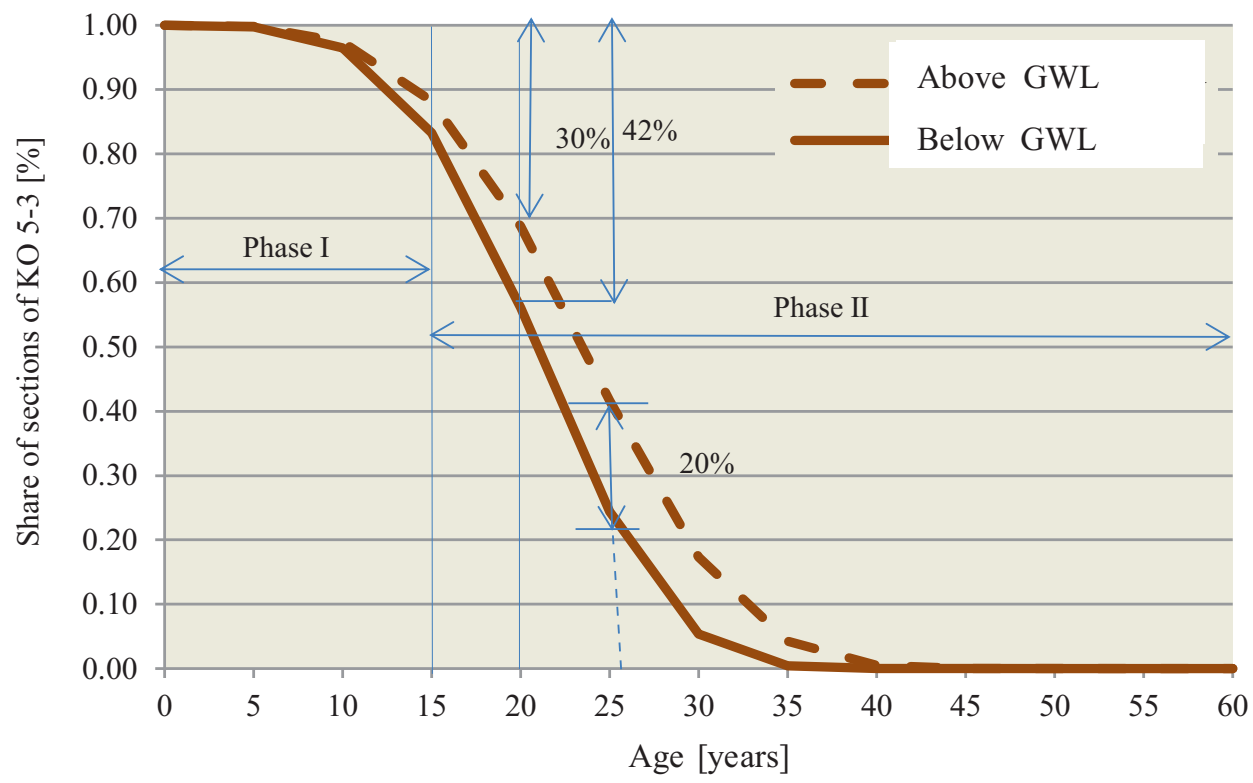

Fig. 7. Course of critical Weibull functions determined by MMC simulation for stoneware connections depending on its position relative to GWL 


\section{Conclusions}

The municipal sewage system transporting sewage from the Hachinger Bach stream catchment area is characterized by very homogeneous boundary conditions that limits its operation. This allowed us to demonstrate analytically and confirm a well-known experience resulting from operational practice. The obtained real test results enabled us to testify that the stochastic modeling of the critical condition of the sewer pipes has an application character and can be transferred to other sewage infrastructures, regardless of the boundary conditions of their operation. The basic condition of the applicability of the proposed methodology is the reality of the empirical material. This requirement is wagered to all statistical analysis. It also has a direct impact on the quality of stochastic modeling.

The actual advantages of the proposed modeling of the technical and operation critical state of the sewage system will be verified by practical applications. The model has a universal character and its application range is broad, covering many areas of municipal management. These include water supply systems, rainwater management, road and bridge exploitation, and state of the groundwater and the surface water. The forecasting of ground water levels is an indispensable element of a system of flood safety design and rainwater management.

The original value of the performed scientific statistical and stochastic studies is a new approach for determining both a general and detailed assessment of the technical and operational state of sewage pipes. In order to simplify the traditional forecasting methodology, the concept of the critical technical and operational state was elaborated, defining the boundary between the area reserved for repair and maintenance procedures and the area reserved for renovation techniques.

In analyzes assessing the technical state of the sewer pipes, essential boundary conditions of their functioning were considered. The analyzed sewage network infrastructure operates under homogeneous conditions, which include subsoil, external loads, and transported medium. Therefore, the study focused on assessing the impact of foundation depth, the presence of ground water, operating material, and the functions of the pipe network on the technical and operational condition. In the detailed analyzes, the age structure of the objects was also taken into account and the technical and technological solutions resulting from this insight.

The phase of the statistical survey was based on a two-parameter Weibull distribution; in the phase of stochastic modeling, an innovative tool for mathematical simulations was used using the Monte-Carlo method, which allowed us to significantly increase the number of analyzed random samples and accuracy of the Weibull parameter estimation.

Stochastic modeling of the technical and operational critical state of sewer lines also allowed us to establish the typical operational phases characterized by the corresponding speeds of technical destruction. On the basis of our research and analysis, it was established that the main networks lines (concrete collectors and 
stoneware pipes) can be exploited without intervention for a period of 30 years. For the connections, however, the exploitation period is only 20 years. Meanwhile, the projected service life of the pipes for the first group reached 50-55 years, and for the second $-45-50$ years.

The developed forecasting methodology for the technical and operational critical state of sewer lines requires further research, which will include additional conditions of sewage network functioning in the Hachinger Bach stream catchment area by broadening the base of the empirical data. The increased database will form the basis for the application of other mathematical models to perform more-accurate analyzes and draw more-meaningful conclusions of theoretical importance as well as sewage linear object exploitation relevant for everyday practice.

\section{References}

[1] ATV-M 149, Zustandserfassung, -klassifizierung und -bewertung von Entwässerungssystemen außerhalb von Gebäuden. GFA - Verlag für Abwasser, Abfall und Gewässerschutz, Hennef 1999.

[2] DIN 1986-30, Entwässerungsanlagen für Gebäude und Grundstücke - Teil 30. Beuth Verlag GmbH, Berlin 2003.

[3] DIN 1986-30, Entwässerungsanlagen für Gebäude und Grundstücke - Teil 30. Beuth Verlag GmbH, Berlin 2012.

[4] DIN SPEC 19748, Anforderungen an Schlauchliner zur Renovierung von Abwasser Hausanschlussleitungen. Beuth Verlag GmbH, Berlin 2012.

[5] GEOINFORM, Magellan - GIS in new dimentions. Geoinform Vertriebszentrale, Würzburg 2002.

[6] Kipp B., Möllers K.: Inspizierbarkeit von Grundstücksentwässerungsleitungen. Korrespondenz Abwasser, Nr. 4, 1992, pp. 462-465.

[7] Kölling Ch., Tomsu Ch.: Grundwassermodell - östliche Münchner Schotterebene. Umweltreport der Stadt München, München 2003.

[8] Leisch F.: Computerintensive Methoden - Zufallszahlen. Institut für Statistik der Ludwig-Maximilians-Universität, München 2011.

[9] Müller-Gronbach T., Novak E., Ritter K.: Monte Carlo-Algorithmen. Springer-Verlag, Berlin - Heidelberg 2012.

[10] Münchner Normalien, Zentrale Technische Normen für Kanalbau in München. Stadtentwässerung, München 1992.

[11] Raganowicz A.: Besonderheiten der Kanalsanierung in Unterhaching. UmweltBau, Nr. 5, 2007, pp. 94-96.

[12] Raganowicz A.: Technische Aspekte der Kanalsanierung im Hachinger Tal, I. [in:] Dziopak J. (red.), Infrastruktura komunalna a rozwój zrównoważony terenów zurbanizowanych. I Ogólnopolska Konferencja Naukowo-Techniczna INFRAEKO 2008, Politechnika Rzeszowska, Rzeszów 2008, p. 179-192. 
[13] Steinzeug - Ein komplettes Programm für die moderne Abwasserkanalisation, Handbuch. Steinzeug GmbH, Köln 1998.

[14] Verordnung über Anforderungen an das Einleiten von Abwasser in Gewässer (Abwasserverordnung - AbwV). Bundesgesetzblatt, Bonn 2004.

[15] Weibull W.: A statistical distribution function of wide applicability. Trans. ASME, Serie E: Journal of Appl. Mechanics, 18, 1951, pp. 293-297.

[16] Wilker H.: Weibull-Statistik in der Praxis, Leitfaden zur Zuverlässigkeitsermittlung technischer Komponenten, Band 3. Books on Demand GmbH, Norderstedt 2010.

\section{Stan krytyczny sieci kanalizacyjnej}

Streszczenie W artykule przedstawiono metodykę modelowania statystyczno-stochastycznego krytycznego stanu technicznego sieci kanalizacyjnej. Stan krytyczny badanego obiektu zdfiniowano jako przejście przewodów kanalizacyjnych od stanu konserwycji do stanu rehabilitacji technicznej.

Badania modelowe obejmują kolektory betonowe DN 600/1100, DN 800/1200, DN 900/1350 mm, przewody kamionkowe DN 200-400 mm i przyłącza kamionkowe DN 100-200 mm. Modelowanie statystyczne oparto na rozkładzie Weibulla, a estymację jego parametrów na metodzie momentów. Natomiast modelowanie stochastyczne przeprowadzono na podstawie kombinacji rozkładu Weibulla z metodą Monte-Carlo. Ustalenie krytcznego stanu pozwala na szczegółową ocenę techniczną badanej sieci kanalizacyjnej.

\section{Słowa}

kluczowe: sieć kanalizacyjna, stan krytyczny, rozkład Weibulla, metoda Monte-Carlo 